\title{
Video-assisted anal fistula treatment (VAAFT): a novel sphincter-saving procedure to repair complex anal fistulas: response to comment by Chivate
}

\author{
A. P. Zbar
}

Received: 11 June 2012/ Accepted: 24 July 2012/Published online: 6 September 2012

(C) Springer-Verlag 2012

\section{Dear Sir,}

Dr. Chivate [1] raises some important technical considerations pertaining to the ease (or otherwise) of the procedure [2]. We know, for example, from the work of Buchanan and colleagues that preoperative imaging does not readily identify the subepithelial course of fistulae, and this group has previously suggested that a more acute angle of entry of the fistula is associated with a higher traversal through the sphincteric musculature [3]. These fistulae, more angled at their point of entry, may result in more sphincter destruction when conventional means of treatment particularly where larger staple "volcanoes" may need to be created to establish closure of the presumptive internal opening. It would be of interest to know the histology of these volcano excisions and whether they contain internal sphincter muscle.

We now have glues, plugs, LIFTs, BIOLIFTs, FilAC lasers, regenerative cells, advancement anoplasties (with or without internal sphincter division) and now VAAFT for the treatment of complex recurrent fistulae. When each is suitable or contraindicated is at present unclear and like all of our fistula literature, this will depend on the longer term fidelity of our follow-up, our recording of specific procedure-related complications and particular fistularelated functional quality of life estimates. These data simply are not yet available. The VAAFT offers a nice minimally invasive approach with small wounds and limited sphincteric damage, it lends itself to repeat surgery should it fail, and it is unlikely to compromise the chances of repeat-VAAFT success. I too am interested in what to do with that very angulated or circuitous fistula which the VAAFT scope cannot negotiate. Further, can VAAFT deal with the obtuse side track or the fistula lying in an abscess cavity and disconnected from its proximal extension? What are the best electrodes to employ with VAAFT and should volcanoes be supported by mucosal advancement? Finally, what do we do in those cases where there is no visible external fistula opening?

Conflict of interest The author states no declared conflict of interest in submitting this letter.

\section{References}

1. Dhondiram Chivate S (2012) Comment on Meinero and Mori: Video-assisted anal fistula treatment (VAAFT): a novel sphinctersaving procedure to repair complex anal fistulas. Tech Coloproctol. doi:10.1007/s10151-012-0873-y

2. Meinero PC, Mori L (2011) Video-assisted anal fistula treatment (VAAFT): a novel sphincter-saving procedure to repair complex anal fistulas. Tech Coloproctol 15:417-422

3. Buchanan GN, Williams AB, Bartram CI, Halligan S, Nicholls RJ, Cohen CR (2003) Potential clinical implications of direction of a trans-sphincteric anal fistula track. Br J Surg 90:1250-1255

\footnotetext{
A. P. Zbar $(\square)$

Department of Surgery and Transplantation (affiliated with the Sackler School of Medicine and Tel Aviv University), Chaim Sheba Medical Centre, Tel Aviv, Israel

e-mail: apzbar1355@yahoo.com
} 